industrias rurales", incluye a diferentes mamíferos (camello, llama, antílopes, ñu, etc.) y aves (avestruz, ganso de Egipto, faisán de América, pato de la Carolina, etc.). Arch. M.N.C.N. "Fondo Graells-Apuntes científicos", caja 13 , expediente 26 , documento I.

6. Carta (1 folio) con membrete del Ministerio de Fomento-Agricultura, tramitando el expediente al marqués de Monistrol, presidente del citado Consejo. Arch. M.N.C.N., "Fondo GraellsApuntes científicos", caja 13, expediente 26, documento II. El escrito lleva fecha de 10-II1882.

7. Carta ( 1 folio) del marqués de Monistrol, con membrete del Consejo de Agricultura ("Sección $1^{\text {a }}$ Presidencia"), dirigida al "Excmo. Sr. D. Mariano de la Paz Graells". Arch. M.N.C.N., "Fondo Graells-Apuntes científicos", caja 13, expediente 26, documento III, el escrito lleva fecha de 2-VI-1882.

8. Comienza el escrito de Atienza a Graells: "Le remito esta carta con el fin de saber, sin pérdida de tiempo, si mi expediente ha pasado al Consejo y si está en poder de Ud. Cuando reciba contestación escribiré al $1^{\text {er }}$ director de Agricultura. Varios primeros de Málaga me han preguntado por las semillas de vides americanas y he hablado con su sobrino, que me ha dicho haberle escrito...". Arch. M.N.C.N., "Fondo del RJB. Inventario somero de los años 1775-1938", caja n 7 , expediente de la "Asociación de Agricultura de España, etc.". Aunque no está fechado, es posible que el escrito fuera remitido el 1-III-1882.

Dirección del autor: Juan PÉREZ-RUBíN. Centro Oceanográfico de Málaga. Instituto Español de Oceanografía. Muelle Pesquero s/n. 29640 Fuengirola (Málaga).

\title{
35. LAS RELACIONES DE MARIANO DE LA PAZ GRAELLS (1809-1898) CON LA ACADEMIA DE CIENCIAS NATURALES Y FÍSICAS DE MÁLAGA EN 1841.
}

\author{
Juan PÉREZ-RUBÍN
}

Según cuatro cartas custodiadas en el Museo Nacional de Ciencias Naturales (MNCN, Fondo Graells-Caja n 1: "Exped. 5/Caja 1"), las primeras relaciones de Graells con Málaga parecen remontarse al mes de abril de 1841. A la sazón tenía 32 años de edad y, desde 1837, era catedrático de Zoología en el MNCN y miembro de la Real Academia de Ciencias de Madrid.

En dicho año 1841 recibe Graells dos cartas de la Academia de Ciencias Naturales y Físicas de Málaga (ACNFM). En la primera misiva, sin fecha, el secretario de gobierno de la ACFNM
(Eduardo Gilly), le notifica su nombramiento de académico correspondiente, confiando en "que contribuirá a la propagación y adelantos de las ciencias [naturales]", y corresponderá "acompañando las tareas que se pongan a su cuidado". En la segunda carta de la ACFNM (20/ 4/1841, dirigida a la c/del León, 13; Madrid), firmada por A. J. Velasco ('secretario de correspondencia’?), se le pregunta a cual sección desea pertenecer (Ciencias Naturales o Físicas) y a que rama de la investigación "se dedica particularmente". 
Una semana después (27/4/1841), contesta Graells por separado a ambos remitentes. Al primero (E. Gilly) tras manifestar su "agradable sorpresa" por el nombramiento y agradecer el diploma acreditativo recibido, alaba las condiciones de la región: "Ese país favorecido por la naturaleza, ese lucero de la Península, atrae de continuo las miradas de todos los naturalistas de Europa; a él se dirigen con preferencia y dentro de poco serán sus producciones naturales más conocidas que las del resto de España". Cita seguidamente las recientes investigaciones de $\mathrm{F}$. Webb, E. Boissier y M. Rambur en tierras andaluzas ("son obras que están en el día o concluidas o concluyéndose (...) y que solo tienen por objeto dar a conocer las novedades naturales de la fértil Andalucía"). Seguidamente expone sus deseos de "que esta gloria recaiga en adelante sobre la ACNFM (...), y que jamás consintamos, por nuestra desidia, que los sabios extranjeros nos arrebaten los laureles que sólo nosotros debemos recoger, porque [esas producciones naturales] crecen en nuestro suelo patrio". Finaliza Graells el escrito poniéndose a su disposición ("no debe dudar la Academia que estaré siempre pronto a secundar sus ideas benéficas") y felicitándola por su establecimiento.

Al segundo remitente (A. J. Velasco) contesta Graells (desde c/Amaniel, 11; Madrid) aclarando que desea ser incluido en la sección de Ciencias Naturales de esa Academia, indicándole que sus investigaciones se centraban especialmente en la zoología y la botánica, y concretando que venía desempeñando en el MNCN la cátedra de Zoología.

Aceptado para su publicación en abril de 2002

Dirección del autor. Centro Oceanográfico de Málaga. Instituto Español de Oceanografía. Muelle Pesquero s/n. 29640 Fuengirola (Málaga).

\title{
36. UN MANUSCRITO INÉDITO DE MARIANO DE LA PAZ GRAELLS (1809- 1898) SOBRE LA ACLIMATACIÓN DE PLANTAS EN MÁLAGA
}

\author{
Juan PÉREZ-RUBÍN
}

En el Museo Nacional de Ciencias Naturales se conserva un manuscrito de Graells, sobre sus observaciones relativas a especies vegetales aclimatadas en la capital malagueña y alrededores (MNCN. Fondo Graells-Caja n ${ }^{\circ}$ 1: "Exped. 5/ Caja 13").

El documento en cuestión, sin fecha ni título, ocupa dos folios subdivididos en cuartillas.
Comienza el texto: "Plantas que yo he visto en Málaga aclimatadas hace tiempo y vegetando, [tanto] al aire libre en varias fincas como en el propio país, y cuyo hecho viene a comprobar plenamente la adaptación en aquel clima de muchos vegetales de Indias, pudiendo acrecerlos con infinitos otros de parecidas procedencias". Tras enumerar una treintena de "plantas exóticas intertropicales, muchas de ambos hemisferios", 